\title{
EL CURSO DE CONOCIMIENTOS PREVIOS Y LA ACCIÓN TUTORIAL: REFLEXIONES DESDE LA PRÁCTICA
}

\author{
PREVIOUS KNOWLEDGE CONTENTS AND TUTORIAL ACTIVITIES: \\ REFLECTIONS FROM DE PRACTICE
}

\author{
F. Javier Barbas González, Consuelo Fernández Jiménez, Ignacio Gómez Pérez, \\ $M^{a}$ Dictinia Pérez Vázquez y Pedro Plaza Menéndez* \\ Universidad Politécnica de Madrid \\ (Escuela Universitaria de Ingeniería Técnica Aeronáutica)
}

\section{RESUMEN}

Se describen las acciones desarrolladas en la "Escuela Universitaria de Ingeniería Técnica Aeronáutica" (E.U.I.T.A.) de la "Universidad Politécnica de Madrid" (U.P.M.) para mejorar la calidad del proceso educativo de los estudiantes en su primer año en la universidad. Este proyecto incluye un curso de revisión de conocimientos antes del comienzo de las clases lectivas y un plan de acción tutorial durante este primer año. Se han realizado una serie completa de pruebas y entrevistas para medir su efectividad y se han comparado los resultados del grupo seleccionado con los del resto de alumnos de nuevo ingreso. Los resultados, han sido muy positivos, en especial a la hora de aumentar la motivación de los estudiantes en el estudio de las distintas asignaturas del primer curso.

Palabras claves: Mejora del rendimiento académico, plan de acción tutorial, calidad de las enseñanzas universitarias, motivación de los estudiantes universitarios.

\begin{abstract}
This document describes the activities developed in the "Escuela Universitaria de Ingeniería Técnica Aeronáutica" (E.U.I.T.A.) at the "Universidad Politécnica de Madrid" (U.P.M.) in order to improve the cuality of the educat process for students in their first university year. The related activities have included a knowledge review course before the beginning of the normal classes and a tutorial action
\end{abstract}

\footnotetext{
* Profesores Titulares de Escuela Universitaria. Universidad Politécnica de Madrid. Escuela Universitaria de Ingeniería Técnica Aeronáutica. Plaza del cardenal Cisneros, s/n, 28040 Madrid. E-mail: consuelo.fernandez@ upm.es. Participan en varios Proyectos de Innovación Educativa y en Experiencias Piloto de curso completo de implantación de créditos ECTS. Líneas actuales de investigación: programas de acción tutorial, desarrollo de nuevas metodologías de aprendizaje/evaluación, incorporación de nuevas tecnologías a la formación presencial.
} 
plan during the full first year. A comprehensive set of tests and interviews have also been administered to measure the effectiveness actions in the selected student group compared with the rest of students in their first year. The results have been quite positive, especially in the area of motivating the students in the study of the different subjects of the first year.

Key Words: Improvement of academic achievement, tutorial activities, university teaching/learning quality, university student motivation.

"El objeto de la investigación educativa consiste en desarrollar una reflexión atenta con objeto de fortalecer el juicio profesional de los profesores"

L. Stenhouse

\section{Descripción de las acciones realizadas}

Esta experiencia se llevó a cabo en la Escuela Universitaria de Ingeniería Técnica Aeronáutica de la Universidad Politécnica de Madrid (EUITA) en el curso 2004/05 con una muestra de 60 alumnos de nuevo ingreso elegidos aleatoriamente de un total de 350. El proyecto consta de dos partes claramente diferenciadas: una antes del inicio del curso académico con un "Curso práctico de conocimientos previos" (C.C.P.) y otra, de seguimiento y acción tutorial durante el curso ordinario ${ }^{1}$.

\section{Curso de conocimientos previos}

El Curso de conocimientos previos tenía como objetivos actualizar los conocimientos ya adquiridos en estas materias, uniformizar el nivel de los alumnos que provienen de orígenes diversos y, al mismo tiempo, acostumbrarlos al ritmo de trabajo universitario.

Se impartió a lo largo de las dos semanas de septiembre anteriores al comienzo del curso ordinario, con una duración total de treinta horas. La asistencia a clase era obligatoria, permitiéndose un máximo del $20 \%$ de ausencias justificadas. Se utilizó como material de trabajo un cuaderno de ejercicios prácticos, facilitado al alumno al inicio del curso, y el "Curso interactivo de matemáticas con MAPLE", que estaba a su disposición en el aula de informática de la Escuela.

El enfoque fue eminentemente práctico e individualizado, dando prioridad al trabajo personal del alumno a la hora de tratar los contenidos ${ }^{2}$ y de establecer el ritmo más adecuado. Cada grupo de treinta alumnos era atendido por dos profesores y los conceptos se trabajaban a partir de la resolución por parte de dichos alumnos de distintos problemas propuestos ad hoc. También se propusieron ejercicios que debían resolver en casa. Estos ejercicios, una vez corregidos y con toda clase de anotaciones, les eran devueltos y comentados.

1. Fundamentaciones teóricas a estos procedimientos se pueden encontrar en el Informe Bricall, III-54 y en Alañón (2000).

2. Conceptos generales de funciones, Funciones polinómicas y racionales, Funciones trigonométricas, Funciones exponenciales y logarítmicas, Límites de funciones, Continuidad de funciones, Cónicas y Vectores. 


\section{La Acción tutorial a lo largo del curso}

Su objetivo era facilitar la adaptación e integración de los alumnos al sistema formativo superior mediante el seguimiento directo de la actividad académica, personal y profesional ${ }^{3}$. También permitiría recoger información acerca de sus necesidades, sus hábitos de trabajo y su visión de la Universidad en general y sobre la Escuela en particular.

A cada grupo de alumnos de la misma especialidad se le asignó un profesor tutor y, en la medida de lo posible, se mantuvo el criterio de que el tutor fuera a su vez profesor en alguna asignatura. La forma habitual de contactar fue mediante correo electrónico o directamente en las clases en las que se coincidía con ellos.

Además de las tutorías individuales a petición de cada alumno, se mantuvieron reuniones periódicas con cada grupo. Cabría destacar la tutoría llevada a cabo tras conocer los resultados del primer cuatrimestre y para la que se preparó una ficha específica con el fin de reflexionar sobre las causas de estos resultados.

\section{Resultados y evaluación}

La evaluación se ha divido en cuatro apartados que aparecen por orden cronológico, donde se muestran, de forma telegráfica, sólo los resultados y las conclusiones que se han creído más significativos. Están disponibles todos los datos, el procedimiento de obtención, su manejo estadístico, así como una valoración más detallada de los mismos.

\section{Resultados del test inicial de contenidos}

Fue realizado por todos los alumnos de nuevo ingreso y existen marcadas diferencias en el resultado medio de los alumnos que realizaron el curso de conocimientos previos y el resto, siendo más alta la media obtenida por los alumnos que han asistido al curso.

\section{Encuestas de satisfacción}

Los 58 alumnos que completaron las primeras encuestas de satisfacción realizadas después del curso, admitían su aprovechamiento; concretamente la pregunta "Globalmente, mi valoración del curso ha sido" recogió una puntuación de 4,28 sobre 5. También hubo valoración muy positiva a los contenidos, formas y desarrollo del curso. Se hizo otra encuesta de satisfacción en el mes de marzo, una vez conocidas las calificaciones en las asignaturas del primer cuatrimestre. La opinión generalizada respecto al C.C.P. siguió siendo positiva, todos recomendarían hacerlo a los alumnos de nuevo ingreso. La mayoría pensaba que el C.C.P. era útil para acostumbrarse al ritmo de la Escuela, para mejorar la comunicación con los profesores y para facilitar el estudio de las asignaturas de física y matemáticas. Sin embargo, parecía existir un desencuentro por haber un salto excesivo entre el curso cero y las asignaturas de las titulaciones. También parecían existir ligeras contradicciones entre las

3. Los procedimientos seguidos estuvieron inspirados en autores como Arias (2005) y Álvarez (2002). 
dos encuestas, producidas por el paso del tiempo y por los malos resultados, en general, obtenidos en las asignaturas del primer cuatrimestre. Así, si los contenidos seleccionados para el curso cero aparecían con un 4,20 de media (sobre un máximo de 5), en las encuestas realizadas cinco meses después había disminuido el grado de satisfacción sobre esa selección. Aunque la idea de reducir el apoyo informático ya apareció tímidamente en la primera encuesta, en la segunda es mucho más tajante.

\section{Comparación de los resultados académicos con el grupo de control}

Otro de los aspectos que se ha tenido en cuenta al evaluar las acciones llevadas a cabo, ha sido la "eficacia" a la hora de aprobar las asignaturas. Se han comparado los resultados académicos de la muestra y del grupo de control después de cada cuatrimestre. Un resumen de estos resultados se pueden ver en la tabla 1 .

TABLA 1: Indicadores de resultado en el año académico 2004-2005 para cada población en las asignaturas: Física I, Cálculo I, Álgebra Lineal, Química y Tecnología Aeroespacial.

\begin{tabular}{|l|c|c|}
\hline Indicadores de resultado & Alumnos del curso previo & Resto de alumnos de nuevo ingreso \\
\hline Tasa de rendimiento* $I_{2}$ & $32,96 \%$ & $31,46 \%$ \\
Tasa de éxito $I_{3}$ & $52,70 \%$ & $56,39 \%$ \\
Tasa de motivación $I_{M}$ & $62,54 \%$ & $55,79 \%$ \\
\hline
\end{tabular}

* Tasa de rendimiento: Créditos aprobados/Créditos matriculados. Tasa de éxito: Créditos aprobados/Créditos presentados. Tasa de motivación: Créditos presentados/Créditos matriculados

La principal conclusión sería que el número de créditos aprobados por ambas poblaciones es prácticamente el mismo. No obstante, hay una diferencia notable en cómo se alcanza ese valor medio en los dos grupos. Así se tiene que sólo el 5,4\% de los alumnos del C.C.P. no aprueba un mínimo de 6 créditos (normativa de permanencia de la U.P.M), frente al $22,3 \%$ del resto de los alumnos de nuevo ingreso. Dada la normativa de permanencia de la UPM, cabe señalar la reducción significativa en el número de alumnos que no pueden proseguir sus estudios, reduciéndose a la cuarta parte el fracaso en el primer año. Así podrán continuar sus estudios en la Escuela el 94,6\% de los alumnos del C.C.P., frente al 77,7\% del resto de los alumnos. Por otra parte, el valor medio de la Tasa de motivación es superior en los alumnos de la muestra.

\section{Resultados de la acción tutorial}

En general, los temas planteados en las reuniones conjuntas del grupo con su profesor tutor guardan una relación directa con el momento concreto del curso y reflejan su perspectiva de éxito en ese momento. Inicialmente, llenos de optimismo y seguros de sus posibilidades, sus preguntas giran en torno al modo de acceso a la Escuela Técnica Superior de Ingenieros Aeronáuticos para realizar el segundo ciclo, cómo conseguir becas en empresas, salidas profesionales, futuro de estas titulaciones dentro del nuevo EEES, conveniencia de 
compaginar estos estudios con otros de idiomas, etc. Después de conocer los resultados del primer cuatrimestre, son más frecuentes las cuestiones relativas a permanencia, tercera convocatoria, restricciones impuestas en las normas de matriculación, asignaturas de libre elección, conveniencia de presentarse a pocas asignaturas, etc.

En cuanto a su método de estudio, en general dedican una media de 2,5 horas diarias (dato que parece insuficiente dada la abundancia de contenidos), aunque reconocen que no estudian de modo regular las asignaturas. Alrededor del 50\% compaginan las clases en la Escuela con la ayuda de las academias.

Para abordar el segundo cuatrimestre existe una coincidencia total en la decisión de abandonar "a priori" las asignaturas de mayor contenido y presentarse a un máximo de tres nuevas, influenciados quizás por los resultados del primer cuatrimestre y por los consejos de los alumnos repetidores. Sin embargo, en cuanto a las academias hay una gran dispersión de opiniones en función de su experiencia en el primer cuatrimestre. Hay alumnos que no las utilizarán para ninguna asignatura, otros para alguna $\mathrm{y}$, excepcionalmente, hay un alumno que sólo asistirá a clases de academia.

\section{Conclusiones}

Teniendo en cuenta los resultados, podríamos concluir que las acciones realizadas han influido positivamente en el proceso de aprendizaje de los alumnos que las han llevado a cabo y en su grado de satisfacción ${ }^{4}$.

Sin embargo, se comprueba que: asistir y aprovechar el curso cero es aconsejable pero en absoluto suficiente para aprobar las asignaturas. Para salvar este salto entre el C.C.P. y las asignaturas se podría elevar el nivel de los contenidos en la medida que fuera posible, aumentar los contenidos y/o la duración del curso, y ampliarlo a otras asignaturas.

La acción tutorial debe comenzar desde el inicio del curso, extenderse a todos los alumnos de nuevo ingreso, e intentar que se convierta en una actuación sistemática y coordinada entre todos los tutores. Algunas de estas propuestas de actuación han sido ya puestas en práctica en cursos sucesivos.

\section{Referencias bibliográficas}

Alañón Rica, M Teresa (2000). Un modelo de acción tutorial en la Universidad Politécnica de Madrid. Madrid: Alañón Rica.

Álvarez, P. (2002). La función tutorial en la universidad; un apuesta por la enseñanza. Madrid: EOS.

Apocada, P. y Grao, J. (1996): “Autoevaluación planificación estratégica y calidad total”. En F. J. Tejedor y J. L. Rodríguez Diéguez (Eds). Evaluación Educativa II: Evaluación Institucional. Fundamentos teóricos y aplicaciones prácticas. Salamanca: Instituto Universitario de Ciencias de la Educación de la Universidad de Salamanca.

Arias Hernández M Ma M., Alvarez Pérez P. R., García Andrés Mª C., Cabrera Figueroa J., Martín del Río Aguilar Ma D., y Robayna Delgado M ${ }^{\mathrm{a}}$ C. (2005). "La tutoría como respuesta a las necesida-

4. Entendemos como Apocada (1996:82) la satisfacción personal un indicador de calidad por excelencia. 
des del alumnado universitario: un estudio en el primer curso de Enfermaría de la Universidad de la Laguna". REOP, Vol 16, 2, 319-331.

Bricall, J. M. y cols. (2000). Informe Universidad 2000. Revista Vivat Academia, 16. Madrid: UAH

UNIVERSIDAD CARLOS III DE MADRID (2005). Curso cero para alumnos de nuevo ingreso. http://www.uc3m.es/uc3m/serv/GA/PROF/seguimientoyresultado.html

Fecha de recepción: 28-09-05

Fecha de revisión: 23-01-07

Fecha de aceptación:08-05-07 